\section{Exponential growth}

Herb F. Sewell

European Cytokine Network. Editors-inchief Jacques Bertoglio and Didier Fradelizi. John Libbey Eurotext, 6 rue Blance, 92120 Montrouge, France. $6 / y r$. France FF1,100, rest of Europe $\$ 195$, elsewhere $\$ 195$ (institutional); France FF850, rest of Europe $\$ 135$, elsewhere $\$ 150$ (personal); France FF500, rest of Europe $\$ 90$, elsewhere $\$ 105$ (student).

DURING the past decade, the growth of data in publications covering the biological, biochemical, biophysical and clinical applications of cytokines has been strikingly exponential. It has been nearly impossible for even the most dedicated basic researchers, users of cytokines and clinicians to keep up with all the latest developments. What they required was a publication of original, comprehensive, concise, informative and up-to-date articles. These requirements have now been ably met by the European Cytokine Network journal. The editors' intention of providing the community with a publication of interest to a large audience has been excellently maintained; this journal 'networks' scientists and practitioners in immunology, molecular biology, oncology, physiology - indeed in most of the recognized 'ologies' - informing them of the latest developments in the unifying subdiscipline of 'cytokine-ology'.

The members of the distinguished editorial board have worked hard and stuck to their brief: original articles reflect state-of-the-art science and comprehensively cover most cytokines without the usual overemphasis on the prototypic molecules such as the interleukins 1 and 2 and granulocyte-macrophage colonystimulating factor. It is noteworthy that for original articles there is a gap of four to six weeks between reception and acceptance, with publication usually within eight to ten weeks.

Another attractive aspect of the journal is the comprehensive scientific reviews and mini-reviews, some six or four pages of highly informative, well referenced and thought-provoking commentary by leading experts. There are also occasional detailed technical papers, crucial for evaluating the science in this burgeoning field. The journal's continued good performance and quality is in part due to the welcome practice of commissioning notable annual guest editors. The quality of the illustrations and the print has undergone considerable improvement, and the journal's annual subscription rates compare very favourably with journals in other specialist disciplines.

Although we will all continue to browse in our libraries, chase our CDROMs and listen attentively at 'update meetings', there is no doubt that this journal represents one of the best attempts at networking the discipline and the disciples of cytokines. If one is interested in bridging the gap from cytokine biophysics, to biology, to bedside, then this journal is a must. Its genesis was most timely, and its infancy and formative first two years indicate that it will continue to nurture and network its readers.

Herb F. Sewell is in the Department of Immunology, University Hospital, Queen's Medical Centre, Nottingham NG7 2UH, UK.

\section{Mass media}

\section{J. K. Heath}

Growth Regulation. Editor D. Schulster. Churchill Livingstone. 4/yr. \$240, £137 (institutional); \$191, £109 (personal).

THE origins of research on growth factors lie in many fields, but a major contribution came from developments in endocrinology. Nowadays 'growth factors' are perhaps more associated in the minds of readers of Nature with cell or developmental biology, although there has always been a steady undercurrent of important growth-factor work published in the mainstream endocrinology journals. This has been especially true for work on circulating growth factors such as growth hormone and the insulin-like growth factors (IGFs or somatomedins). Growth Regulation is aimed at capturing this segment of the market. Indeed, growth - as in size - is exactly what the journal is all about and most of the papers are devoted to studies of growth factors that control body mass.

In Growth Regulation one is, therefore, more likely to read about RIA and IGF than RNA and FGF. Most papers in the first few issues are devoted to various aspects of the IGFs, including studies in both cell culture and human subjects. So if the journal is going to be a long-term success, it will probably be as the somatomedin-fraternity house journal rather than as a direct threat to the main established endocrinology journals. It certainly remains to be seen whether it can spread from this niche and truly reflect the interdisciplinary approach to growth regulation predicted in its opening leading article.

The editors do, in fact, have some- thing of a dilemma on their hands. Given the interest in the subject from outside the scientific community, the control of body mass is bound to be a problem that attracts increasing attention, some of which is likely to be anecdotal rather than scientifically rigorous. This is illustrated by one of the weakest papers in the opening issues, a study of IGF levels in prepubertal female gymnasts undergoing intensive training. I was caught between wanting a better piece of science and the potential implications, which otherwise might as well be summarized as 'Don't put your daughter on the beam Mrs Worthington'. Despite these misgivings, the general quality of many of the contributed papers in the early issues is reasonable. The journal also includes review articles and a useful literature survey. Like most new journals, Growth Regulation has staked out a niche in the market and will succeed if the niche itself continues to expand.

J. K. Heath is in the Department of Biochemistry, University of Oxford, South Parks Road, Oxford OX1 3QU, UK.

\section{Cancer forum}

\section{David A. Cheresh}

Melanoma Research. Editors Ferdy Lejeune, Guiseppe Prota and Patrick Riley. Rapid Communications of Oxford. $6 / y r . £ 180, \$ 342$.

HUMAN melanoma is widely studied by basic and clinical researchers for several reasons. First, it is among the most malignant cancers known. Second, the metastatic form of this tumour does not respond to treatment. Third, the incidence of melanoma is on the rise. Fourth, there are many cultured melanoma cell lines and animal models for investigation.

So far, many of the published articles on human melanoma have appeared either in strictly basic science or clinical journals. Melanoma Research aims to provide a new international forum for the rapid dissemination of basic and clinical melanoma research. It presents a broad scope of basic articles on biological studies with emphasis on genetic, molecular or biochemical findings. The clinical articles focus on diagnostic approaches and novel therapies and their effectiveness in clinical trials.

The standard of the articles is comparable to that of more well established cancer journals. Each issue contains relevant reviews and a good mixture of basic and clinically related articles. The production quality and format seem 